\title{
From Skeptic to Vital Partner in Massage Therapy Research: an Interview with Mark Hyman Rapaport, MD
}

\author{
Ann Blair Kennedy, LMT, BCTMB, DrPH, \\ Executive Editor, IJTMB \\ University of South Carolina School of Medicine Greenville, Greenville, SC, USA
}

Mark Hyman Rapaport, MD is a highly accomplished researcher, academician, and clinician. Dr. Rapaport has more than 180 publications, and his main research interests include biologic genesis of anxiety disorders, as well as immunity abnormalities and depression in mood disorders. His research investigating massage therapy has included study of inflammatory biomarkers, cancer related fatigue, and generalized anxiety disorder. He has created a successful partnership with the Atlanta School of Massage for the implementation of his research inquiry. Dr. Rapaport discusses with us a wide range of topics on massage therapy, including from where his inspiration for research comes.

Just a couple of short hours from me down Interstate 85 , is the vast and eclectic city of Atlanta. The buzzing capital city of Georgia is birthplace of the civil rights movement in the USA, was the host of the 1996 Olympic Games, and is home to dozens of quality higher education institutions, including the largest private college in the state, Emory University. $(1,2)$ It is at Emory University School of Medicine where you will find the next subject of our massage therapy researchers interview series, Dr. Mark Hyman Rapaport.

Mark Hyman Rapaport, MD, is a highly accomplished researcher, academician, and clinician. He received his MD from the University of California San Diego School of Medicine, from where he also completed his residency. He also has completed two Postdoctoral Fellowships, one with University of California San Diego Department of Psychiatry and one with the National Institute of Mental Health. Dr. Rapaport was the Polier Chair of the Department of Psychiatry at Cedars-Sinai Medical Center, and a Professor and Vice Chair of Psychiatry at University of California, Los Angeles (UCLA). Currently he is the Reunette W. Harris Professor and Chair of the Department of Psychiatry and Behavioral Sciences, and the Chief of Psychiatric Services for Emory Healthcare.

Dr. Rapaport has more than 180 publications which can be found in a variety of scientific journals from American Journal of Psychiatry to the Journal of
Clinical Psychiatry and the Journal of Alternative and Complementary Medicine. His main research interests include biologic genesis of anxiety disorders, as well as immunity abnormalities and depression in mood disorders. His research interests intersect with massage therapy research when investigating single and multiple sessions of massage therapy of hypothalamic-pituitary-adrenal and immune function, ${ }^{(3,4)}$ how massage therapy can help reduce symptoms of generalized anxiety disorder, ${ }^{(5)}$ and how massage therapy can reduce cancer-related fatigue. ${ }^{(6)}$ Dr. Rapaport is a distinguished fellow of the American Psychiatric Association, and a fellow of CINP and the American College of Neuropsychopharmacology. He is the current President of the American Association of Chairs of Departments of Psychiatry.

\section{PLEASE TELL US ABOUT YOUR MASSAGE THERAPY RESEARCH AND HOW YOU FEEL IT HAS IMPACTED THE FIELD OF MASSAGE THERAPY.}

I have had several studies specifically using massage therapy as an intervention; we have looked at inflammatory biomarkers in healthy individuals, ${ }^{(3,4)}$ cancer-related fatigue, ${ }^{(6)}$ and generalized anxiety disorder. ${ }^{(5)}$ I began with the inflammatory biomarkers study ${ }^{(3,4)}$ and I had hoped that we would be able to describe how massage therapy impacts individuals by applying traditional scientific approaches to the treatment. When we are able to elaborate on the biological mechanisms to describe how and why massage therapy "works", then it will be more acceptable to the rest of the scientific community. I want us, those in massage therapy research, to come up with the best answers, because doing thoughtful research in massage therapy is critical.

In our inflammatory biomarkers study, we found that in this randomized control study there was a significant reduction after one (45-minute) session and a cumulative reduction effect after five weeks of sessions in our biological measures compared to the light touch control group. ${ }^{(3,4)}$ We used the results 
from those studies to move on to populations with some pathologies. We conducted randomized clinical trial with patients with untreated generalized anxiety disorder. Patients received 2 sessions a week of either light touch or Swedish massage for 45 minutes. We found that those in the massage group had a statistically and clinically significant reduction on the measures for anxiety and depression. ${ }^{(5)}$ In the cancerrelated fatigue study, we again used a randomized control study design, but this time we had two control groups - a light tough control and a waitlist control. Our results indicated massage therapy did produce an amelioration of cancer-related fatigue symptoms for the patients. ${ }^{(6)}$ What seems to be interesting to me in these findings is that a stressed and anxious population of patients may need treatment two times per week and, with the patients with fatigue, one session per week may be sufficient.

Throughout my massage therapy research, I have collaborated with massage therapists. The inflammatory biomarkers study was done in collaboration with Joya Savra and the HeartTouch Institute; the generalized anxiety disorder and cancer-related fatigue studies were done in conjunction with the Atlanta School of Massage as a research partner. I feel that there has not been enough done in building the relationships between academic centers and massage therapy programs to increase massage therapy research. We must work with massage therapy training programs to help them to become research institutions and/or research partners.

\section{HOW DID YOU BECOME INTERESTED IN RESEARCHING MASSAGE THERAPY?}

Basically, because I am a skeptic. People were spending billions of dollars on massage therapy, but there was not any evidence on what happens biologically. I was curious to find out what was happening in the body during massage therapy. Also, as a Psychiatrist, I am interested in how the mind and body are connected and I even tell my students and residents: "The mind and the body are connected and that's why God made the neck." So, I just really wanted to find out what was going on during a massage.

\section{HOW DO YOU INTEGRATE STAKEHOLDERS (E.G., PRACTICING MASSAGE THERAPISTS, MASSAGE PATIENTS/CLIENTS) INTO YOUR RESEARCH PLANNING, IMPLEMENTATION, AND/OR DISSEMINATION?}

I think it is important to include massage therapists in the whole research process. In my relationship with the Atlanta School of Massage, we have worked extensively together to create research protocols and training tools. One of those massage therapists, Erika Larson, is also included as an author on both the cancer-related fatigue and the generalized anxiety disorder studies. Also, I believe that those who enter the field of psychiatry need to be aware of the benefits of massage therapy for their patients. I recommend that residents know the risk and benefits of many complementary and integrative health modalities to be able to have informed discussions with patients. ${ }^{(7)}$

\section{WHERE DO YOU SEE THE MASSAGE THERAPY PROFESSION AND/OR MASSAGE THERAPY RESEARCH IN THE NEXT FIVE YEARS?}

I hope we'll be able to do a series of large-scale studies - especially in further investigation into mood disorders like depression and anxiety, but also cancer. I also want to go further and investigate how massage therapy can help those with substance use and misuse conditions.

There are a lot of questions that are still unanswered, and I would be interested in looking at some of those topics as well. For example, how can massage therapy help those with PTSD? Or, how massage therapy could be very helpful in overuse and stress related conditions. Finally, what about investigating how massage therapy could impact those with autoimmune disorders. The problem as always is funding. It can be difficult to find groups willing to provide money to look at the biology of what is happening during and after massage therapy.

\section{IF YOU WERE LIMITED TO JUST ONE PERSON TO GET ADVICE AND HELP FROM, WHICH PERSON WOULD YOU CHOOSE? WHY?}

I do not have just one person, but a group of people, and that would be my patients. My best ideas come from my patients, just talking with my patients and learning from them and listening to them. They teach me so much and help keep me interested in research and medical practice. That is why I continue to see patients to this day.

\section{COPYRIGHT}

Published under the CreativeCommons Attribution-NonCommercial-NoDerivs 3.0 License.

\section{REFERENCES}

1. Emory University. About Emory. 2018. Available from: http:// www.emory.edu/home/about/index.html. Accessed 3 Apr 2018. 
2. Georgia, USA. Georgia Department of Economic Development. Colleges and Universities. Atlanta, GA: Georgia Department of Economic Development; 2018. Available from: http://www. georgia.org/competitive-advantages/education/colleges-anduniversities/. Accessed 3 Apr 2018.

3 Rapaport MH, Schettler P, Bresee C. A preliminary study of the effects of repeated massage on hypothalamic-pituitaryadrenal and immune function in healthy individuals: a study of mechanisms of action and dosage. J Altern Complem Med. 2012;18(8):789-797. doi:10.1089/acm.2011.0071

4. Rapaport MH, Schettler P, Bresee C. A preliminary study of the effects of a single session of Swedish massage on hypothalamicpituitary-adrenal and immune function in normal individuals. J Altern Complem Med. 2010; 16(10):1-79-88. First published online 1 September 2010. doi:10.1089/acm.2009.0634

5. Rapaport MH, Schettler P, Larson ER, Edwards SA, Dunlop BW, Rakofsky JJ, et al. Acute Swedish massage monotherapy successfully remediates symptoms of generalized anxiety disorder: a proof-of-concept, randomized controlled study. J Clin Psychiat. 2016;77(7):e883-891. doi:10.4088/JCP.15m10151
6. Kinkead B, Schettler PJ, Larson ER, Carroll D, Sharenko M, Nettles J, 'et al. Massage therapy decreases cancer-related fatigue: results from a randomized early phase trial. Cancer 2018;124(3):546-554. doi:10.1002/cncr.31064

7. Rakofsky JJ, Cotes RO, McDonald WM, Schwartz AC, Rapaport $\mathrm{MH}$. Beyond the psychiatric horizon: preparing residents for the twenty-first century. Acad Psychiat. 2017;41(1):125131. doi:10.1007/s40596-016-0517-z

Corresponding author: Ann Blair Kennedy, LMT, BCTMB, DrPH, Department of Biomedical Sciences, Division of Behavioral, Social, and Population Health, University of South Carolina School of Medicine Greenville, 701 Grove Road, Greenville, SC 29605, USA

E-mail: Kenneda5@greenvillemed.sc.edu 